\title{
STATUS OF PROPULSION TECHNOLOGY DEVELOPMENT UNDER THE NASA IN-SPACE PROPULSION TECHNOLOGY PROGRAM
}

\author{
David Anderson, Hani Kamhawi, Mike Patterson, Eric Pencil, Luis Pinero \\ David.J.Anderson@nasa.gov \\ NASA Glenn Research Center \\ John Dankanich \\ NASA Marshall Space Flight Center
}

\begin{abstract}
Since 2001, the In-Space Propulsion Technology (ISPT) program has been developing and delivering in-space propulsion technologies for NASA's Science Mission Directorate (SMD). These in-space propulsion technologies are applicable, and potentially enabling for future NASA Discovery, New Frontiers, Flagship and sample return missions currently under consideration. The ISPT program is currently developing technology in three areas that include Propulsion System Technologies, Entry Vehicle Technologies, and Systems/Mission Analysis. ISPT's propulsion technologies include: 1) the 0.6-7 kW NASA's Evolutionary Xenon Thruster (NEXT) gridded ion propulsion system; 2) a $0.3-3.9 \mathrm{~kW}$ Hall-effect electric propulsion (HEP) system for low cost and sample return missions; 3) the Xenon Flow Control Module (XFCM); 4) ultra-lightweight propellant tank technologies (ULTT); and 5) propulsion technologies for a Mars Ascent Vehicle (MAV). The NEXT Long Duration Test (LDT) recently exceeded 50,000 hours of operation and $900 \mathrm{~kg}$ throughput, corresponding to $34.8 \mathrm{MN}$-s of total impulse delivered. The HEP system is composed of the High Voltage Hall Accelerator (HIVHAC) thruster, a power processing unit (PPU), and the XFCM. NEXT and the HIVHAC are throttle-able electric propulsion systems for planetary science missions. The XFCM and ULTT are two component technologies which being developed with nearer-term flight infusion in mind. Several of the ISPT technologies are related to sample return missions needs: MAV propulsion and electric propulsion. And finally, one focus of the Systems/Mission Analysis area is developing tools that aid the application or operation of these technologies on wide variety of mission concepts. This paper provides a brief overview of the ISPT program, describing the development status and technology infusion readiness.
\end{abstract}

\section{INTRODUCTION}

Missions carried out for the Planetary Science Division (PSD) of NASA's Science Mission Directorate (SMD) seek to answer important science questions about our Solar System. To enable or significantly enhance PSD's future planetary science missions, the In-Space Propulsion Technology (ISPT) program is developing critical propulsion, entry vehicle, and other spacecraft and platform subsystem technologies. The objective is to achieve technology readiness level (TRL) 6 and reduce risk sufficiently for mission infusion. The ISPT program aims to develop technologies in the mid TRL range (TRL 3 to $6+$ range) that have a reasonable chance of reaching maturity in 4-6 years. ISPT strongly emphasizes developing propulsion products for NASA flight missions that will be ultimately manufactured by industry and made equally available to all potential users for missions and proposals. ISPT focuses on the development of new enabling technologies that cannot be reasonably achieved within the cost or schedule constraints of mission development timelines.

ISPT started in 2001 and has been developing in-space propulsion technologies that will enable and/or benefit near and mid-term NASA robotic science missions by significantly reducing cost, mass, risk, and/or travel times. ISPT technologies will help deliver spacecraft to PSD's future destinations of interest. The ISPT program is currently developing technology in four areas. These include Propulsion System Technologies (Electric and Chemical), Entry Vehicle Technologies (Aerocapture and Earth entry vehicles), Spacecraft Bus and Sample Return Propulsion Technologies (components and ascent vehicles), and Systems/Mission Analysis. These in-space propulsion technologies are applicable, and potentially enabling, for future NASA Discovery, New Frontiers, and sample return missions currently under consideration, as well as having broad applicability to potential Flagship missions.

ISPT's propulsion system technology investments are currently being made in the area of Solar Electric Propulsion (SEP). SEP is both an enabling and enhancing technology for reaching a wide range of targets. Several key missions of interest: sample return, small body rendezvous, multirendezvous, Titan/Saturn System Mission (TSSM), Uranus Orbiter w/Probe, etc., require significant post-launch $\Delta \mathrm{V}$ and therefore can benefit greatly from the use of electric propulsion. [1, 2] High performance in-space propulsion can also enable launch vehicle step down; significantly reducing mission cost. [3] The performance of the electric propulsion systems allows direct trajectories to multiple targets that are otherwise infeasible using chemical propulsion. The technology allows for multiple rendezvous missions in place of fly-bys and, as planned in the Dawn mission, can enable multiple destinations. SEP offers major performance gains, moderate development risk, and significant impact on the capabilities of new missions. ISPT's approach to the development of chemical propulsion technologies is primarily the evolution of component technologies that still offer significant performance improvements relative to state-of-art technologies. The investments focus on items that would provide performance benefit with minimal risk with respect to the technology being incorporated into future fight systems. This paper describes the technology development in the areas of electric propulsion, propulsion components, Mars ascent vehicle, and mission/systems analysis. For more background on ISPT, please see References [4, 5, 6, 7, 8].

\section{NASA's EVOLUTIONARY XenOn Thruster}

The NASA's Evolutionary Xenon Thruster (NEXT) ion propulsion system was developed for a wide range of NASA robotic science missions, including near-term New Frontiers 
and Discovery class mission opportunities. The GRC-led NEXT project was competitively selected to develop a highly throttle-able $7 \mathrm{~kW}$ ion propulsion system. [4, 5] The objectives of this development were 1) to improve upon the state-of-art (SOA) NASA Solar Electric Propulsion Technology Application Readiness (NSTAR) system flown on Deep Space-1 and Dawn, 2) to enable flagship class missions by achieving the performance characteristics identified in Table 1.

Table 1. Performance Characteristics of NEXT vs. NSTAR SOA

\begin{tabular}{|lcc|}
\hline \multicolumn{1}{|c}{ Characteristic300 } & $\begin{array}{c}\text { NSTAR } \\
\text { (SOA) }\end{array}$ & NEXT \\
\hline Thruster Power Range (kW) & $0.5-.3$ & $0.5-6.9$ \\
\hline Max. Thrust (mN) & 92 & 236 \\
\hline Max. Specific Impulse (sec) & $>3100$ & $>4100$ \\
\hline Max. Thruster Efficiency & $>61 \%$ & $>70 \%$ \\
\hline Total Impulse (x10 ${ }^{6}$ N-sec) & $>5$ & 35.5 \\
\hline Propellant Throughput (kg) & 135 & 918 \\
\hline PPU Specific Mass (kg/kW) & 6.0 & 4.8 \\
\hline PMS Single String Mass (kg) & 11.4 & 5.0 \\
\hline PMS Unusable Propellant Residual & $2.40 \%$ & $1.00 \%$ \\
\hline
\end{tabular}

The ion propulsion system components developed under the NEXT project included the ion thruster, the powerprocessing unit (PPU), the xenon feed system, and a gimbal assembly. The NEXT thruster was developed to TRL6 via the fabrication and successful environmental testing of a prototype-model (PM) fidelity thruster manufactured by Aerojet Rocketdyne Corporation. To demonstrate the performance and life of the NEXT thruster, a comprehensive test program was executed involving both NEXT Engineering Model thrusters and components and the NEXT PM thruster. The NEXT PM thruster completed a 2000 hour wear test in which overall ion-engine performance was steady with no indication of performance degradation. The NEXT PM thruster subsequently passed qualification level environmental testing, both thermal vacuum and vibration testing.

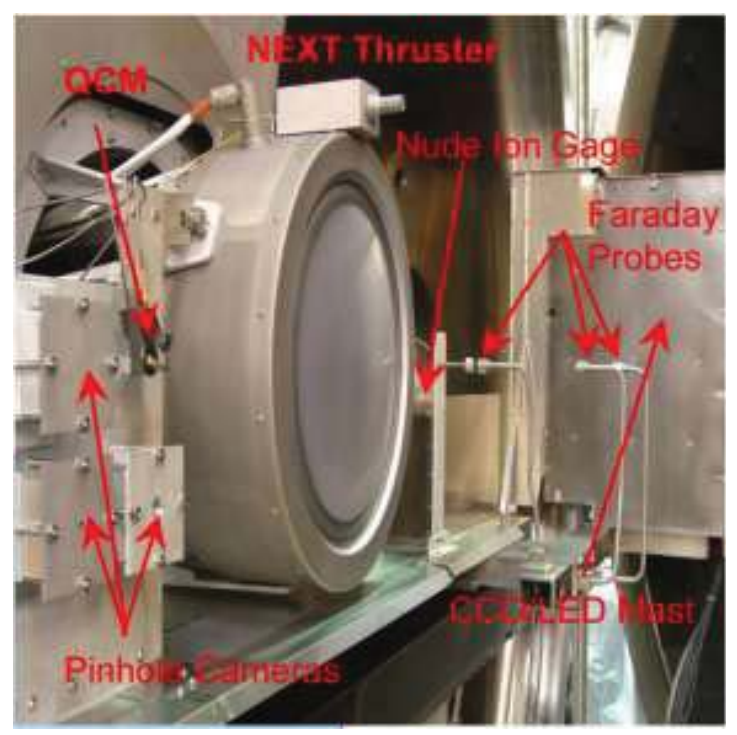

Figure 1 - NEXT LDT Diagnostics

The Long Duration Test (LDT) of the NEXT engineering model (EM) thruster recently completed a 9-year test, demonstrating over $918 \mathrm{~kg}$ propellant throughput, 51,200 hours operation, and 35.5 million Newton seconds total impulse. The test was voluntarily concluded in March 2014, with the thruster capable of operating over the entire throttle range at the end of the test. During the final phase of the test, repairs of several of the in-situ diagnostics that had failed over the test duration were completed, without exposure of the thruster to atmosphere. The repair of the diagnostics allowed for collection of end-of-test data for comparison to beginning-of-life data. The NEXT LDT diagnostics suite is shown in Figure 1, and include a planar probe rake, Residual Gas Analyzer (RGA), a Quartz-Crystal Microbalance (QCM), Ion Gage next to thruster, and lighting for the in-situ photo documentation imaging system. [4]

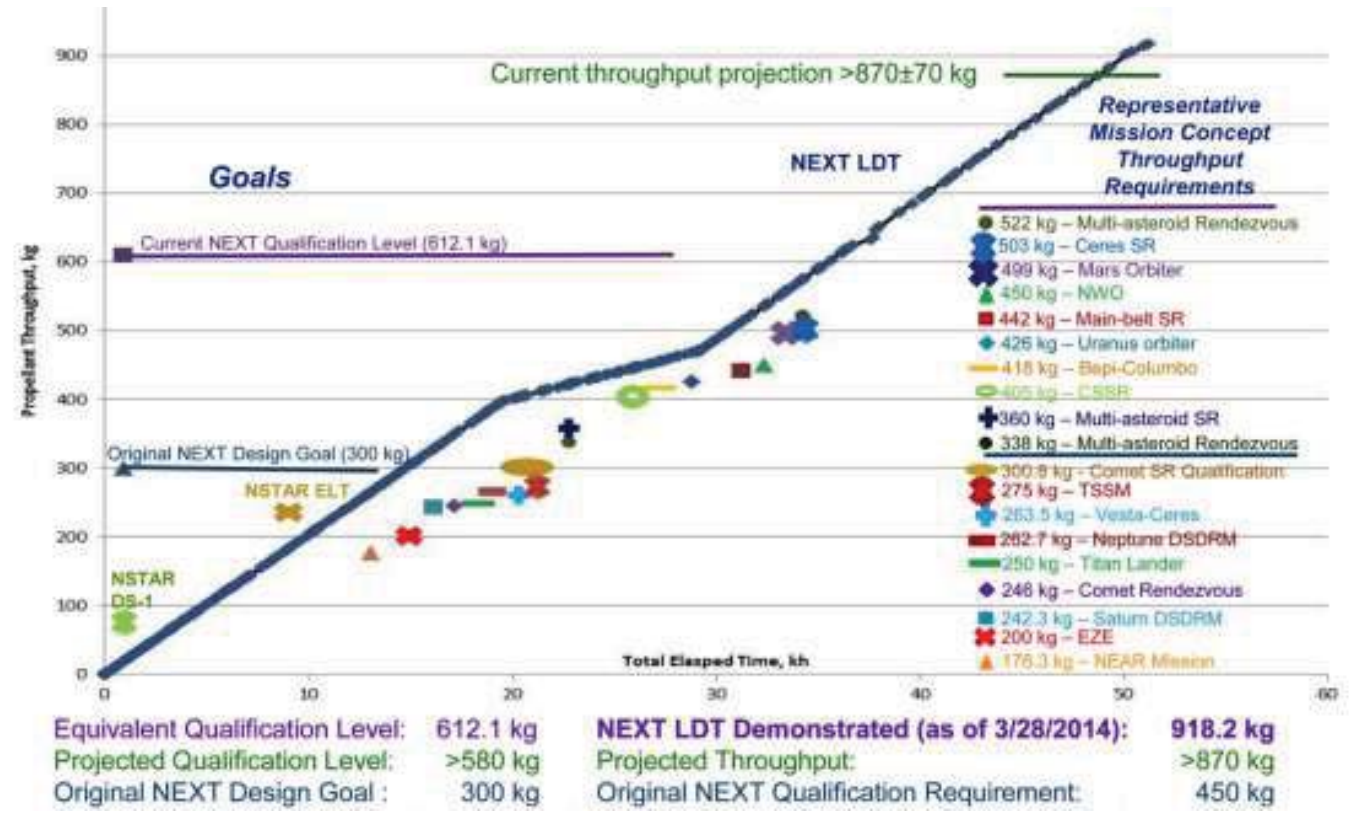

Figure 2-Next Thruster Total Throughput versus representative mission requirements 
The NEXT LDT life test (Figure 2) demonstrated the largest total impulse, highest propellant throughput, and longest operating duration of any electric propulsion thruster in the history of space propulsion. Removal of the thruster and extensive post-test inspections and analyses are now in process (Figure 3). [9] The facility impact assessment conducted prior to examination of the thruster hardware indicates negligible impact on the anticipated spaceequivalent life of the thruster. Back-sputtered facility carbon likely reduced the expected in-space accelerator grid wear about four percent, whereas charge-exchange erosion of the accelerator grid due to residual propellant increased the anticipated in-space erosion by about 8 to 10 percent. [10, 11]

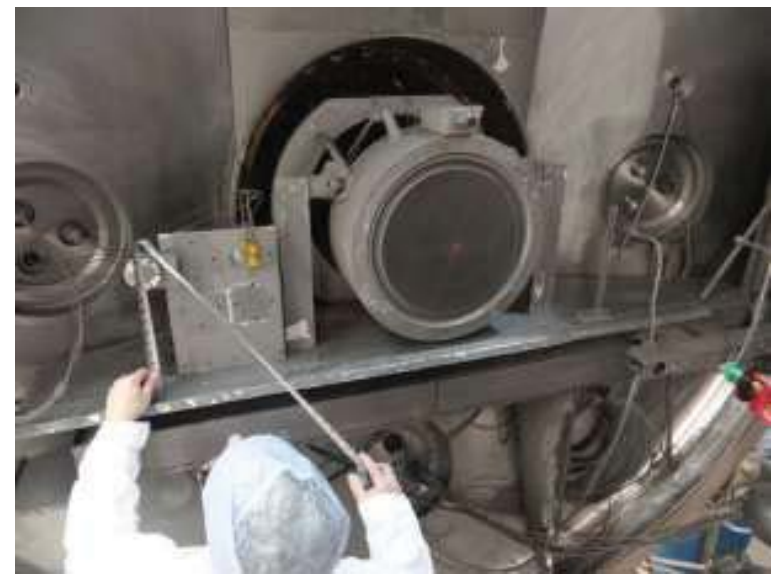

Figure 3 - NEXT LDT Thruster post-test inspection

A collaborative test program with The Aerospace Corporation (TAC) in El Segundo, CA examines the plume, particle, and field environments of the NEXT thruster. A series of measurements was completed to verify basic characteristics of NEXT operation, and expand on the available public-domain and internal databases regarding NASA technology and its potential use on non-NASA spacecraft systems. Among the work elements underway are in-depth electromagnetic interference, plume particle and plasma probe, optical emission, laser diagnostic measurements, plume erosion and molybdenum contamination effects, absolute thrust and thrust correction factors. This work is of considerable relevance to future spacecraft

integration of the subject thrusters. $[12,13,14$,$] Figure 4$ shows the NEXT thruster installed in the vacuum facility at TAC. Among the work elements going forward are detailed characterizations of accelerator grid wear over the entirety of the NEXT thruster throttle table via Laser Induced Fluorescence spectroscopy of eroded products, as

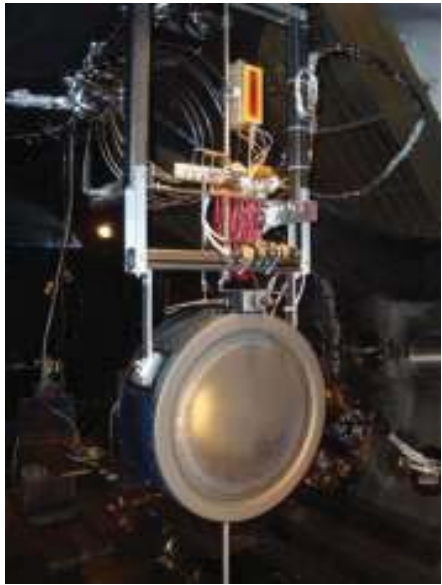

Figure 4-NEXT characterization testing at TAC well as plume (beam divergence and beam charge state) measurements of the thruster over nominal and expanded throttling ranges.

One of the challenges of developing the NEXT ion propulsion system was the development of the Engineering Development Model Unit PPU, shown in Figure 5. The test program identified a number of part problems that required extensive investigations to resolve and implement corrective actions, [15] typical of parts problems experienced in technology development projects.

One of the more interesting part problems was the failure of multi-layer ceramic (MLC) capacitors in multiple beam power supplies. The investigation process utilized an extensive and knowledgeable team that investigated all branches of the fault tree. The corrective actions identified that a custom-built MLC had piezoelectric properties that made it susceptible to an oscillating current in the beam supply circuit. The corrective actions in this case were to replace the custom-build MLC capacitor as well as to eliminate the oscillating current. [16] The corrective actions for the MLC capacitor issues were implemented in the EM PPU, and resolved the problems.

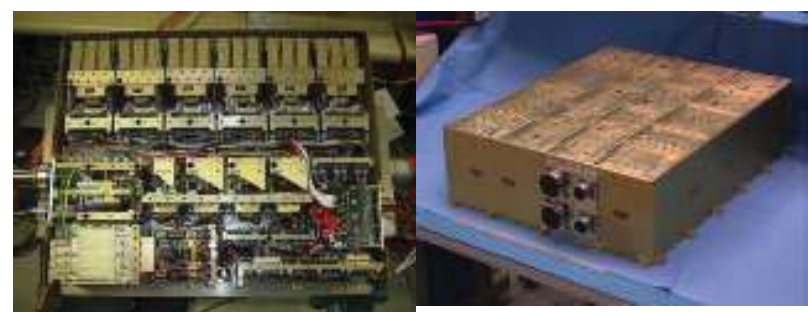

Figure 5 - NEXT PPU developmental unit

A major review of NEXT Phase 2 development activity was conducted in late 2012. A key outcome from the review was the formation of a multi-organization team to define a PPU maturation plan. The technical team assessed verification gaps and PPU design weaknesses that needed to be addressed. The team completed EEE parts and high voltage component assessments, reviewed and updated PPU requirements, and created a Safety and Mission Assurance Plan in preparation for future PPU development. In parallel, the existing PPU was reassembled for use as a test bed to support continuing design evaluation.

The PPU parts issues precluded completion of environmental testing of the PPU and full TRL6 validation. Go-forward planning of the PPU involves development of dual-use PPU under a government-industry partnership to complete TRL6 and transition to flight. Most recently, the Planetary Science Division (PSD) announced that it is considering providing two NEXT thrusters and PPUs as Government-Furnished Equipment (GFE) to mission proposers as part of an upcoming Discovery Announcement of Opportunity (AO). NASA Glenn is working with PSD to finalize development plans in alignment with the anticipated AO release this fall. Additional information on the NEXT system can be found in the NEXT Ion Propulsion System Information Summary in the New Frontiers and Discovery Program libraries. $[9,17,18]$ 


\section{High Voltage Hall Accelerator}

ISPT is investing propulsion technologies for applications to low-cost Discovery-class missions and Earth-Return Vehicles for large and small bodies. The first example leverages the development of a High-Voltage Hall Accelerator (HIVHAC) thruster into a lower-cost electric propulsion system. [4, 19] Advancements in the HIVHAC thruster include a large throttle range from $0.3-3.9 \mathrm{~kW}$ allowing for a low power operation. It results in the potential for smaller solar arrays at cost savings, and a long-life capability to allow for greater total impulse with fewer thrusters. The benefits include cost savings with a reduced part count and less-complex lower-cost propulsion system.

HIVHAC is the first NASA electric propulsion thruster specifically designed as a low-cost electric propulsion option. It targets Discovery and New Frontiers missions and smaller mission classes. The HIVHAC thruster does not provide as high a maximum specific impulse as NEXT, but the higher thrust-to-power and lower power requirements are suited for the demands of some Discovery-class missions and sample-return applications.

After several design changes to the first HIVHAC engineering development unit (EDU-1), the new unit designated EDU-2 underwent the performance acceptance test (PAT). Vacuum Facility 12 (VF-12) at NASA GRC) was used to conduct the PAT, given the pumping speed and resulting vacuum chamber background pressure. The results indicate that performance and operational requirements met expectations, with significant improvement to the thermal margins of key components. Vibration testing was completed with performance tests conducted both before and after vibration tests. The HIVHAC EDU-2 thruster was successfully vibration tested to approximately $11.5 \mathrm{~g}$ in three axes, which were consistent with the specifications used to qualify the NEXT ion thruster. Preliminary visual inspection of the thruster indicates that the thruster passed the vibration testing with no visual damage evident, and no change in thruster performance was measured.

Component integration tests of major HIVHAC system components was conducted in NASA GRC Vacuum facility 5 , as shown in Figures 6 and 7. [20] During the test, thrust, currentvoltage (I-V) characteristics, and a number of plasma diagnostics were implemented to study the effect of varying the facility background

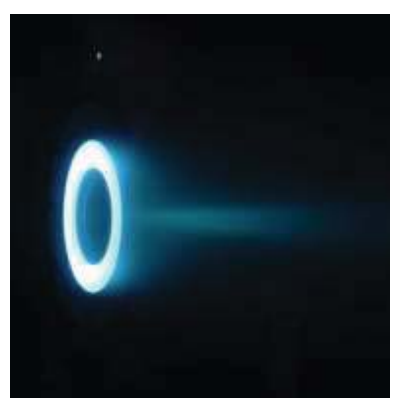

Figure 6- HIVHAC thruster Engineering Development Unit (EDU) pressure on thruster operation. [21] These diagnostics include thrust stand, Faraday probe, ExB probe, and retarding potential analyzer. [22] The test results indicated a rise in thrust and discharge current with background pressure. The I-V characteristics also varied with background pressure. [21] Test results indicated that the thruster discharge specific impulse and efficiency increased as the facility background pressure was elevated. The voltage-current profiles indicated a narrower stable operating region as the background pressure was increased from the lowest attainable background pressure to three and ten times. Experimental observations of the thruster operation at high discharge voltages indicated that increasing the facility background pressure shifted the ionization and acceleration zones upstream towards the thruster's anode [21]. There was a decrease in ion energy per charge, an increase in multiply-charged species production, a decrease in plume divergence, and a decrease in ion-beam current with increasing background pressure. $[22,23]$ Future tests of the HIVHAC thruster will be performed at facility background pressure conditions that are lower than $1 \times 10^{-6}$ Torr.

The HIVHAC EDU-2 thruster advancement mechanism on inner and outer boron nitrate channels was successfully demonstrated immediately after thruster hot-fire operation in VF-12. The advancement mechanism showed smooth advancement of both channels as a full qualification vibration test post-test validation of the mechanism. The actuation test was conducted immediately following thruster shutdown, assuring high-temperature conditions within the thruster. In the future, the test sequence will include performance acceptance tests, the remaining thermal vacuum environmental tests, and a long duration wear test. Current plans include the design, fabrication, and assembly of a full Hall propulsion system that can meet a variety of Discovery and Earth Return Vehicle needs.
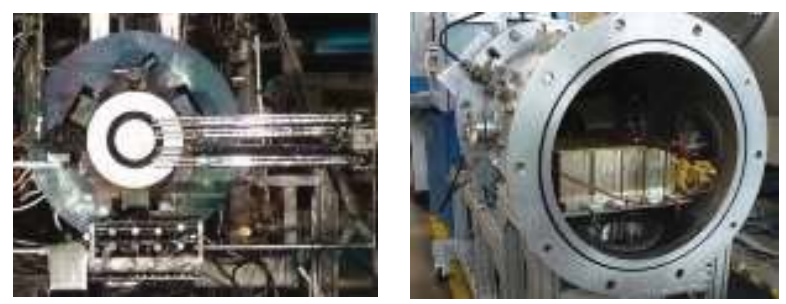

Figure 7 - HIVHAC EDU Thruster and Colorado Power SBIR PPU undergoing performance testing

In addition to the thruster development, the HIVHAC project is evaluating power processing unit (PPU) and xenon feed system (XFS) development options. These were developed under other efforts, but can apply directly to a Hall Propulsion system. The goal is to advance the TRL level of key components of a Hall propulsion system (thruster, PPU/DCIU, feed system) to level 6 in preparation for a first flight.

The functional requirements of a HIVHAC PPU are operation over a power throttling range of 300 to $3,900 \mathrm{~W}$, over a range of output voltages between 200 and $650 \mathrm{~V}$, and output currents between 1.4 and $15 \mathrm{~A}$ as the input varies over a range of 80 to $160 \mathrm{~V}$. A performance map across these demanding conditions was generated for one candidate option $[4,19]$ that is being developed through the NASA Small Business Innovation Research (SBIR) Program. [24] In 2013 a second brass board unit was received from Colorado Power Electronics. Over 2,000 hours of steadystate operation under vacuum conditions have accumulated on this unit. In the summer of 2014 an engineering model (EM) unit will be delivered to NASA GRC. The EM unit will have the form and fit of the flight unit in addition to having a digital control module unit that will control PPU and xenon feed system operation (Figure 8). 


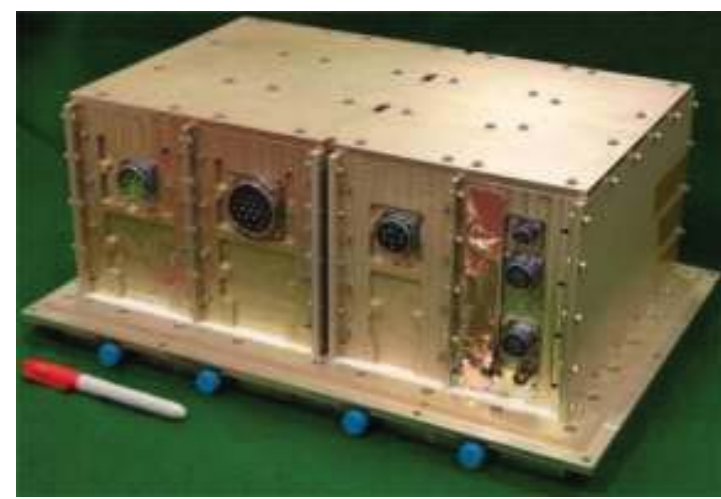

Figure 8-Colorado Power Electronics Hall propulsion system Power Processing Unit.

To continue to simplify and reduce the cost of the HIVHAC system, the ISPT program leveraged the reliable, lightweight, and low-cost xenon flow control system. [25] A follow-on contract was awarded to VACCO as a joint ISPT and Air Force effort to qualify a Hall system flow control module. This module would significantly reduce the cost, mass, and volume of a Hall thruster xenon control system while maintaining high reliability and decreasing tank residuals. This is the first time the ISPT program advanced a component technology to TRL 8 to further reduce the risk and cost of the first user. The new Hall module, shown in Figure 9, completed its qualification program in June 2012. Another version will be qualified at the end of 2014 with onboard electronics to accommodate additional Hall systems currently based on the Moog xenon flow controller; increasing infusion potential. The VACCO module is planned for inclusion in a HIVHAC thruster long duration wear test along with the SBIR PPU as an integrated string test of the HIVHAC system.

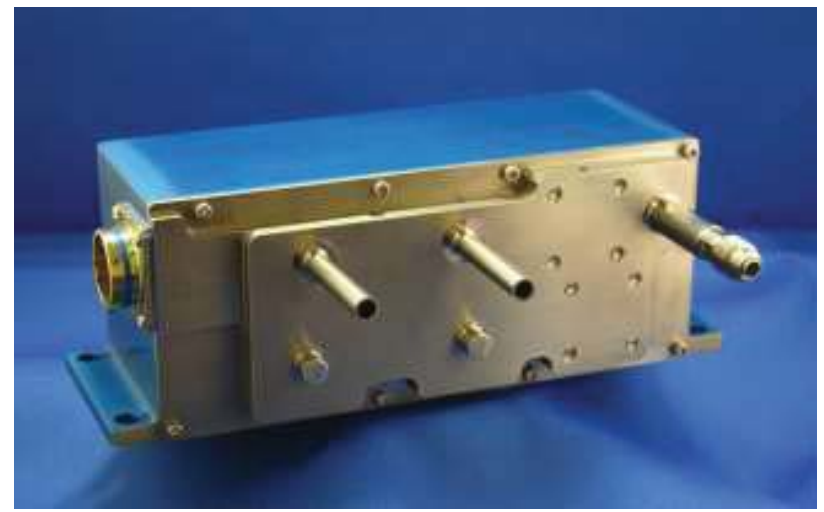

Figure 9- Hall thruster xenon flow control module.

The Near-Earth Object (NEO) mission was evaluated, and the HIVHAC thruster system delivered over 30 percent more mass than the NSTAR system. The performance increase accompanied a cost savings of approximately 25 percent over the State-of-the-Art (SOTA) NSTAR system. The Dawn mission was evaluated, and the expected HIVHAC Hall thruster delivered approximately 14 percent more mass at substantially lower cost than SOA, or decreasing the solar array provided equivalent performance at even greater mission cost savings. [4,20] ISPT has also been assessing commercial Hall systems for planetary science mission applicability. The program funded additional life-testing of the BPT-4000 thruster to extend the demonstrated total impulse and life capability.

A Hall system Technical Interchange Meeting (TIM) was held December 2013 to discuss the state of recent Hall thruster testing and development. The following priorities were identified: 1) the development of a common flight Hall 4.5kW-class modular PPU with capabilities for PSD mission needs for any Hall thruster (COTS or NASA developed), and then to qualify unit and procure three flight PPU's as GFE; 2) the evaluation of commercial Hall thrusters (BPT-4000 (XR-5), SPT-140), and looking at delta qualification (as necessary) for planetary science mission environments/life, assess test facility effects, and develop ground-test-to-flight-modeling protocols; 3) the completion of a HIVHAC system, to assess/incorporate magnetic shielding, and qualify the thruster; 4) leverage STMD Hall system developments for planetary science mission needs; and 5) maintain mission analysis capabilities and tool development for SEP. For more HIVHAC information, see References [19, 20, 21, 22, 24].

\section{Mars Ascent Vehicle Propulsion}

For many years, NASA and the science community have asked for a robotic Mars Sample Return (MSR) mission. There were numerous studies to evaluate MSR mission architectures, technology needs and development plans, and top-level requirements. Because of the technical and financial challenges of the MSR mission, NASA initiated a study to look at MSR propulsion technologies through the ISPT Program Office. The largest new propulsion risk element of the MSR campaign is the Mars Ascent Vehicle (MAV). The current architecture for the MSR lander is to use the Mars Science Laboratory (MSL) entry, descent, and landing (EDL) system. [26] Using the MSL sky crane concept places significant environmental, physical envelope and mass limitations on the MAV system options.

Beyond the limitations of the EDL system, the MAV has specific requirements to deliver the orbiting sample (OS) into an orbit suitable for the Earth Return Vehicle (ERV) to rendezvous with and capture the sample. Many of the subsystem requirements of the MAV are still to be determined, with many to be defined by the prime integrator during development. However, the driving top-level requirements of the MAV are described in References [5, 27].

The environmental requirements for the mission are a critical challenge for the MAV. The environmental requirements include the Earth launch, transit within the cruise stage, the Mars EDL, and finally a long surface stay on Mars. The environments anticipated to influence the system design are the vacuum environment during cruise, the $15 \mathrm{~g}$ quasi-static lateral load during EDL, and the diurnal temperature cycling, during the surface stay. The thermal requirements necessitate a thermal enclosure or "igloo" in order to maintain practical lander power requirements. A detailed set of requirements and system design standards and guidelines has been established for all study participants to ensure comparable system capability and margins. [28]

Through the NASA Research Announcement (NRA) process, the ISPT program solicited MAV system designs and plans to initiate propulsion system development. 
Multiple contractors were selected to proceed in October of 2010 and efforts were initiated in February 2011. Awards were made to ATK, Lockheed Martin, and Northrop Grumman to develop MAV concepts using solid-solid, solid-liquid, and liquid-liquid 1st and 2nd stage propulsion systems respectively. During the NRA efforts, the contractors completed Principal Investigator led collaborative engineering designs of the MAV and began contract options to develop the required technologies in early FY12. Additionally, Firestar Technologies is working, under an SBIR, to develop a Nitrous Oxide Fuel Blend propulsion system applicable to the MAV. [29] The results of the industry efforts indicate that while technology development remains, there are multiple paths to meet performance and requirements of the Mars Ascent Vehicle. The industry efforts and designs are documented in four 2012 IEEE Aerospace Conference papers. [27, 30, 31, 32] The baseline MAV concept design is shown in Figure 10. The Government baseline design is pre-decisional and for understanding design trades and sensitivities, and does not represent any concept selection.

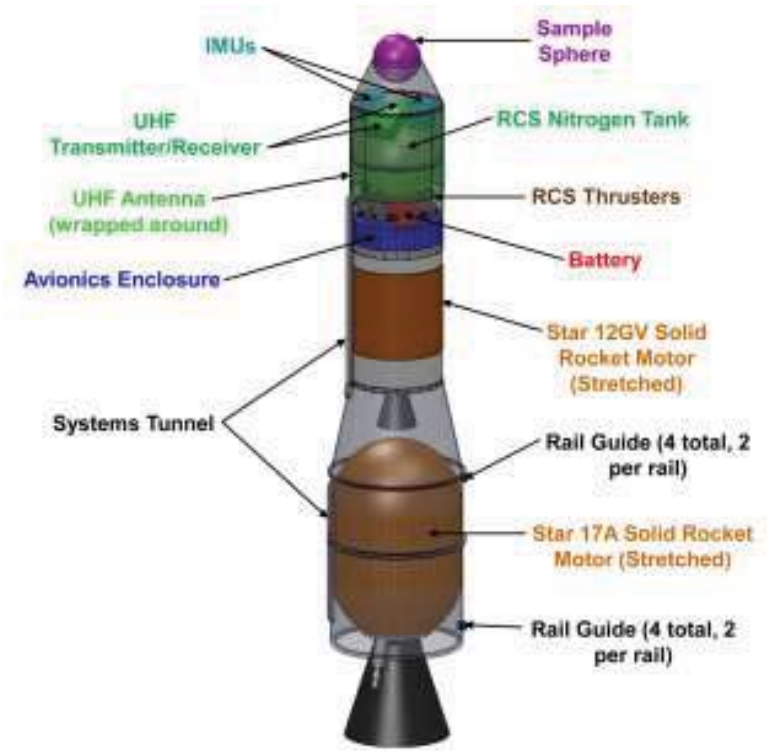

Figure 10 - Government Baseline MAV Concept Design

NASA performed system design studies with the Jet Propulsion Laboratory's (JPL) Team-X and GRC's COMPASS teams. [27] The collaborative designs included a system level optimization using the industry designs and an internal "leveled" design to allow comparison of system mass, complexity, and maturity. The trades included the MAV support systems and lander impacts to minimize the total landed mass. The preliminary results of the studies indicate that the baseline solid-solid system appears to offer the lowest mass solution. The solid-liquid option has slightly higher mass, imposing more thermal requirements on the lander, but can reduce dispersion errors. The liquid-liquid option has the highest mass growth potential due to its mass fraction relative to a solid motor, but requires the least lander resources and has very tight dispersions. The preliminary NOFBx system evaluation indicates it may be a competitive option, but is unlikely to offer a single stage to orbit solution with a lower mass than the two-stage solid.
Each of the MAV concepts was evaluated for risk and technology maturity and additional technology development work was recommended, primarily in the propulsion elements. The MAV NRA work initially focused on the key risks of the individual propulsion systems at the component level. The MAV project team hoped to address the key risks of each option and determine the final viability of various concepts. If the most promising MAV concept(s) was viable with respect to mass, volume, and risks, an integrated propulsion stage demonstration could be the next step. The final step would likely be an engineering model MAV development with an objective of a vehicle terrestrial flight demonstration. However, the MAV technology development in large part has been placed on hold.

Some on-going MAV related studies are being completed, and a long-lead activity to assess the aging of solid rocket motor propellants under Mars environmental conditions (landing shocks and thermal cycling) will proceed until future decisions determine the future MSR architecture and MAV requirements (Figure 11). NASA initiated the development of a new propellant formulation activity with ATK. NASA and ATK traded a wide range of solid motor propellant formulation options to increase the mechanical properties at low temperatures for hydroxyl terminated polybutadiene (HTPB) and to increase performance for carboxyl terminated polybutadiene (CTPB) formulations. Both HTPB and CTPB propellant options have been found to meet the requirements of the MAV. While CTPB traditionally has better mechanical properties at cold temperature, and CTPB has Mars heritage, neither option has heritage for the anticipated environments of the MAV. The newer HTPB formulation began a long duration aging test in November of 2013 at the Marshall Space Flight Center. The propellant aging facility is shown in Figure 11. The propellant will undergo 18 months of testing including an initial simulation of the Mars transit at high vacuum followed by Mars surface environment of surface pressure and temperature conditions. Samples will be removed at 6month intervals for performance and mechanical property testing.

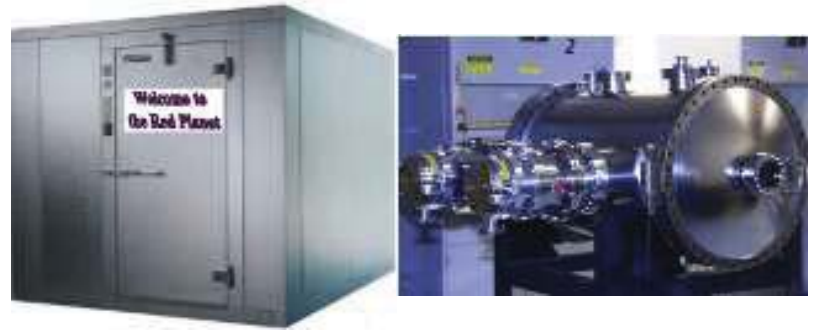

Figure 11 - MAV Solid Propellant Aging Test Chamber

In addition to the propellant aging task, investments are being made to mature the first stage solid motor design for a flexible MAV. Internal JPL studies indicated that a single motor can be designed with flexibility through off-loading propellant to accommodate a MAV design that ranges from a conservative spun upper-stage to a low mass three-axis control second stage. The preliminary design is expected to be completed by June of 2014. 


\section{UltRA LightWEIGHT TANK TECHNOLOGY}

ISPT invests in the evolution of component technologies that offer significant performance improvements without increasing system level risk. The ISPT Program invested in ultra-lightweight tank technology (ULTT) led by JPL. The ULTT efforts in the past focused on manufacturability and non-destructive evaluation of the lightweight tanks. The tank effort continues to validate defect-detection techniques to maintain NASA standard compliance for ultra-thin wall tanks. While this particular tank design is being designed for the Sky Crane application (Figure 12), the ultralightweight technology will be applicable for a wide range of future science missions. Propulsion tanks remain the highest dry-mass reduction potential within chemical propulsion systems. This technology would significantly push the state-of-the-art with the promise of a $2 \mathrm{X}$ improvement over conventional tank designs.

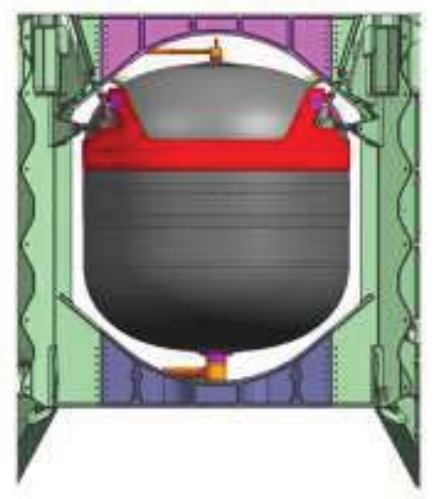

Figure 12 - Ultra-lightweight tank.

The development effort is divided into two main tasks: a Non-Destructive Inspection (NDI) task and the ultralightweight tank design/manufacturing/testing task. The NDI task completed an initial assessment of several NDI techniques, such as eddy-current and surface wave ultrasonic techniques. The results from the tests indicate that these techniques are adequate to find cracks as small as 0.003 inches in the titanium lining. The objective for the NDI task is to establish the crack size that can be detected consistently using these new methods. The ultra-lightweight tank development task would incorporate the NDI technique in the manufacturing and qualification of the new tank.

In order for the tank design to be a success, the approach must demonstrate "safe life." Safe life for non-toxic materials requires proving a design will leak-before-burst. Safe life for toxic liquids, like hydrazine, is more stringent. The NDI technique must be able to detect small cracks in the thin liners, then the NDI results need to be verified, by test, that worst-case crack growth will not grow to failure. An automated eddy current inspection technique has been developed and tested for the detection of small fatigue cracks in thin titanium panels. An improved detection capability promises to find 0.003 inch cracks reliably, which represents a $2 \mathrm{x}$ improvement over SOA detection techniques. Additional information is in References [4, 33] on the NDI work.

The design phase was concluded with a Critical Design Review (CDR), which was held on February 6, 2014.
Significant progress was made in the design and analysis of the propellant tank, but a number of technical challenges still remain. It is recommended that a delta-CDR be held once the NDE and validation methods are fully matured. Unfortunately due to funding constraints, fabrication of a tank will not proceed until additional funding can be found to retire the remaining technical challenges needed to complete the design and pass a delta-CDR, and to proceed onto manufacturing and acceptance/qualification test phases.

\section{SYSTEM/MISSION ANALYSIS}

Systems analysis is used during all phases of any propulsion hardware development. The systems analysis area serves two primary functions:

(1) to define the requirements for new technology development and the figures of merit to prioritize the return on investment,

(2) to develop new tools necessary for mission implementation, and to easily and accurately determine the mission benefits of new propulsion technologies allowing a more rapid infusion of the propulsion products.

Systems analysis is critical prior to investing in technology development. In today's environment, advanced technology must maintain its relevance through mission pull. Systems analysis is used to identify the future mission needs for decadal missions and design reference mission (DRMs). The mission studies identify technology gaps, and are used to quantify mission benefits at the system level. This allows studies to guide the investments and define metrics for the technology advancements. Recent systems analysis efforts include quantitative assessment of higher specific impulse Hall thrusters [34], higher thrust-to-power gridded-ion engines, and evaluation of monopropellant system anomalies to assess failure modes and potential mitigation options. In addition to informing project decisions, the mission design studies provide an opportunity to work with the science and user communities.

The second focus of the systems analysis project area is the development and maintenance of tools for the mission and systems analyses. Improved and updated tools are critical to allow the potential mission users to quantify the benefits and understand implementation of new technologies. A common set of tools increases confidence in the benefit of ISPT products both for mission planners as well as for potential proposal reviewers. For example, low-thrust trajectory analyses are critical to the infusion of new electric propulsion technology. The ability to calculate the performance benefit of complex electric propulsion missions is intrinsic to the determination of propulsion system requirements. Improved mission design tools demonstrate the ability to enable greater science with reduced risk and/or reduced transit times. Every effort is made to have the ISPT program tools validated, verified, and made publicly available. Additional information on the ISPT tools is available at the ISPT website, http://spaceflightsystems.grc.nasa.gov/Advanced/SciencePro ject/ISPT/LTTT/, including background information and instructions to request the software. 
The ISPT office invested in multiple low-thrust trajectory tools that independently verify low thrust trajectories at various degrees of fidelity. The ISPT low-thrust trajectory tools (LTTT) suite includes Mystic [35], the Mission Analysis Low Thrust Optimization (MALTO) [36], Copernicus [37], and Simulated N-body Analysis Program (SNAP). SNAP is a high fidelity propagator. MALTO is a medium fidelity tool for trajectory analysis and mission design. Copernicus is suitable for both low and high fidelity analyses as a generalized spacecraft trajectory design and optimization program. Mystic is a high fidelity tool capable of N-body analysis and is the primary tool used for trajectory design, analysis, and operations of the Dawn mission. While some of the tools are export controlled, the ISPT web site does offer publicly available tools and includes instructions to request tools with distribution limitations. The ISPT systems analysis project team had conducted a series of courses for training on the ISPT supported trajectory tools. On-going tool advancements include providing MALTO and Mystic on all platforms, bug fixes, and increased capabilities.

The ISPT program awarded three Astrodynamics research grants in 2013. The three awards are research and tool development for outer planet moon tours, low-energy trajectories, and a guess tool to initialize Mystic trajectory optimization. The awards were provided to University of Texas-Austin, Purdue University and University of California at Irvine respectively. The efforts were solicited through the SMD ROSES call, started in the spring of 2013, and will conclude in the spring of 2014. The resulting products will be made available to the entire community when complete. Figure 13 is a screenshot from Purdue's low-energy trajectory tool that will interface with GMAT led by NASA GSFC.

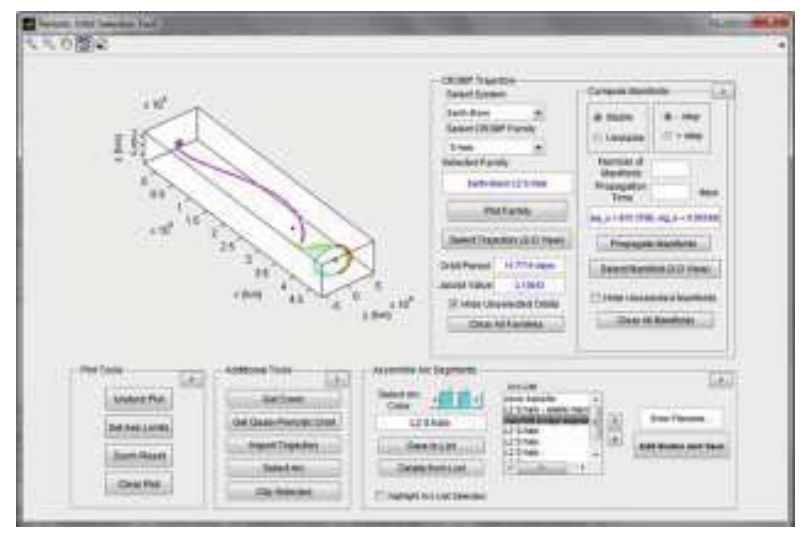

Figure 13 - Low-energy trajectory tool screenshot

\section{CONCLUSION}

The ISPT program is currently funded through FY2014, so the focus this year will be concluding on-going efforts, documenting the accomplishments, and systematically closing-out the program. The ISPT program is making a concerted effort to adjust our remaining development activities to improve the infusion paths for ISPT developed technologies. We are being active in seeking out infusion opportunities for the ISPT developed technologies, and are exploring a number of paths to get our technologies out of NASA and into the commercial world. ISPT is also leading or co-leading several strategic planning activities that include a Technology Infusion Study, a TRL Assessment Study, and the formulation of development plans for Halleffect electric propulsion applicable to Discovery-class missions.

In 2013 and 2014 the NEXT team wraps-up long-duration testing, power processing unit development, and completes closeout documentation. In 2013 HIVHAC completed a test in GRC's VF-5 facility with the same diagnostics suite used for a test of a commercial Hall thruster. This test will help to understand facility effects on Hall thruster testing. The VF-5 facility is undergoing improvements in 2014 to boost its already world-class capabilities, and the program hopes to get the HIVHAC thruster back into the improved facility for another test sequence. HIVHAC will conclude its FY14 activities with verification test of its life extension mechanism, magnetically shielded design iteration, and continued support of the CPE PPU SBIR development. The Ultra-lightweight tank (ULTT) will conclude its development at a CDR in January of 2014. The MAV propellant task will continue through early 2015 with an 18month solid propellant aging test at Mars surface environment conditions.

The Planetary Science Decadal Survey identified the need for future work in propulsion, entry vehicles, and spacecraft bus and other platform technologies. [38] ISPT will continue to work with the PSD to identify the propulsion technologies that will be pursued in the future. ISPT will continue to look for ways to reduce system level costs and enhance the infusion process. If the ISPT program concludes in FY2014, the Space Science Projects Office at NASA Glenn will be available to users who are interested in the ISPT-developed technologies. Regardless, if the mission requires electric propulsion, or a conventional chemical system, ISPT technology has the potential to provide significant mission benefits including reduced cost, risk, and trip times, while increasing the overall science capability and mission performance.

\section{ACKNOWLEDGMENTS}

The results and findings presented here are based on work funded by the National Aeronautics and Space Administration, Science Mission Directorate (SMD). ISPT implements the project through task agreements with NASA centers, contracts with industry, and via grants with academic institutions. Implementing NASA centers include Glenn Research Center, Jet Propulsion Laboratory, and the Marshall Space Flight Center. There are also numerous industry partners in the development of the ISPT products. The authors acknowledge the technical achievements by the respective NASA and contractor teams and the contributions of the respective technology area project managers. In addition, many thanks to Linda Nero for her administrative, editorial, and clerical support of this paper, and to Dan Vento for his editorial reviews and improvements.

\section{REFERENCES}

[1] Dankanich, J. W. and McAdams, J., "Interplanetary Electric Propulsion Uranus Mission Trades Supporting the Decadal Survey," AAS 11-189, AAS/AIAA Space Flight Mechanics Meeting, New Orleans, LA, February 13-17, 2011. 
[2] Dankanich, J. W., "Electric Propulsion for Small Body Missions," AIAA-2010-6614, 46th AIAA/ASME/SAE/ASEE Joint Propulsion Conference \& Exhibit, Nashville, TN, July 25-28, 2010.

[3] Dankanich, J. W., "Launch Vehicle Savings through Advanced In-Space Propulsion," 9th Low Cost Planetary Missions Conference, Laurel, MD, June 21 - 23, 2011.

[4] Anderson, D. J., Munk, M., Pencil, E., Dankanich, J., Glaab, L., and Peterson, T, "The Status of Spacecraft Bus and Platform Technology Development under the NASA ISPT Program," IEEEAC Paper \#2395, 2014 IEEE Aerospace Conference, Big Sky, MT, March 1-8, 2014

[5] Anderson, D. J., Pencil, E., Vento, D., Dankanich, J., Munk, M., Hahne, D., "Propulsion Technology Development for Sample Return Missions under NASA's ISPT Program," AIAA-2011-5766, 47 ${ }^{\text {th }}$ Joint Propulsion Conference, San Diego, CA, July 31 - August 3, 2011.

[6] Anderson, D. J., Pencil, E., Peterson, T., Dankanich, J, and Munk, M., "In-Space Propulsion Technology Products Ready for Infusion on NASA's Future Science Missions," IEEEAC Paper \#1037, 2012 IEEE Aerospace Conference, Big Sky, MT, March 3-10, 2012.

[7] Henderson, S., Stechman, C., Wierenga, K., Miller, S., Liou, L., Alexander, L., and Dankanich, J. W., "Performance Results for the Advanced Materials Bipropellant Rocket (AMBR) Engine," AIAA 2010-6883, 46th Joint Propulsion Conference, Nashville, TN, July 2528, 2010.

[8] Liou, L., Dankanich, J. W., and Alexander, L. L., "NASA In-Space Advanced Chemical Propulsion Development in Recent Years," 2010 IEEE Aerospace Conference, Big Sky, MT, March 6-13 2010.

[9] "NASA's Evolutionary Xenon Thruster (NEXT) Ion Propulsion system Information Summary Aug. 2008," New Frontiers Program Library Website URL: http://newfrontiers.larc.nasa.gov/NFPL.html

[10] Soulas, G., et al., "The Impact of Back-Sputtered Carbon on the Accelerator Grid Wear Rates of the NEXT and NSTAR Ion Thrusters", IEPC-2013-157, $33^{\text {rd }}$ International Electric Propulsion Conference, Washington, DC, October 6-10, 2013.

[11] Shastry, R., et al., Status of NASA's Evolutionary Xenon Thruster (NEXT) Long-Duration Test as of 50,000 $\mathrm{h}$ and $900 \mathrm{~kg}$ Throughput", IEPC-2013-121, $33^{\text {rd }}$ International Electric Propulsion Conference, Washington, DC, October 6-10, 2013.

[12] Pollard, J.E., et al., "Spatially-Resolved Beam Current and Charge-State Distributions for the NEXT Ion Engine," AIAA-2010-6779, 46th AIAA/ASME/SAE/ASEE Joint Propulsion Conference and Exhibit, Nashville, TN, August 2010.
[13] Beiting, E.J., Eapen, X.L., and Patterson, M.J., "Effects on Passing Microwave Beams through an Ion Thruster Plume", Paper No. 1841184, published at Space Propulsion 2010 Conference, San Sebastian, Spain, May 3-6, 2010.

[14] Diamant, K.D., et al., "Thrust Stand Characterization of the NASA Evolutionary Xenon Thruster," Journal of Propulsion and Power 2011, 0748-4658 vol.27 no.4 (777785), doi: $10.2514 / 1.54665$.

[15] Pinero, L., Benson, S. W., "NEXT Engineering Model PPU Development, Progress and Plans," AIAA-20115659, 47th AIAA/ASME/SAE/ASEE Joint Propulsion Conference and Exhibit, San Diego, CA, August 2011.

[16] Soeder J., Scheidegger, R., Pinero, L., Birchenough, A., Dunning, J., NASA's Evolutionary Xenon Thruster (NEXT) Power Processing Unit (PPU) Capacitor Failure Root Cause Analysis", AIAA 2012-4221, $10^{\text {th }}$ International Energy Conversion Engineering Conference, 30 July - 01 August, 2012, Atlanta, GA.

[17] Program Library Website URL: http://discovery.larc.nasa.gov/dpl.html

[18] New Frontiers Program Library Website URL: http://newfrontiers.larc.nasa.gov/NFPL.html

[19] Kamhawi, H., Haag, T., Pinero, L., Huang, W., Peterson, T., Manzella, D., Dankanich, J., Mathers, A., Hobson, D., "Overview of the Development of a LowCost High Voltage Hall Accelerator Propulsion System for NASA Science Missions," AIAA-2011-5520, 47th AIAA/ASME/SAE/ASEE Joint Propulsion Conference and Exhibit, San Diego, CA, August 2011.

[20] Kamhawi, H., et al., "Integration Test of the High Voltage Hall Accelerator System Components," IEPC2013-445, 33rd International Electric Propulsion Conference, Washington, DC, October 6-10, 2013.

[21] Kamhawi, H., et al., "Investigation of the Effects of Facility Background Pressure on the Performance and Voltage-Current Characteristics of the High Voltage Hall Accelerator," IEPC-2013-446, 33rd International Electric Propulsion Conference, Washington, DC, October 6-10, 2013.

[22] Huang, W., et al., "Effect of Background Pressure on the Performance and Plume of the HIVHAC Hall Thruster", IEPC-2013-058, 33rd International Electric Propulsion Conference, Washington, DC, October 6-10, 2013.

[23] Lee, B., et al., "Real-Time Boron Nitride Erosion Measurements of the HIVHAC Thruster via Cavity RingDown Spectroscopy", IEPC-2013-119, 33rd International Electric Propulsion Conference, Washington, DC, October 6-10, 2013.

[24] Pinero, L. R., Kamhawi, H., and Drummond, G., "Integration Testing of a Modular Discharge Supply for NASA's High Voltage Hall Accelerator Thruster", 31st International Electric Propulsion Conference, 2009-275, Ann Arbor, MI, 20-24 Sep., 2009. 
[25] Dankanich, J. Cardin, J., Dien, A., Netwall, C., Osborn, M., and Kamhawi, H., "Advanced Xenon Feed System (AXFS) Development and Hot-fire Testing," AIAA-20094910, 45 ${ }^{\text {th }}$ Joint Propulsion Conference, Denver, CO, August 2-6, 2009.

[26] Mattingly, R., and May, L., "Mars Sample Return as a Campaign," IEEEAC Paper \#1805, 2011 IEEE Aerospace Conference, Big Sky, MT, March 5-12, 2011.

[27] Dankanich, John W., and Klein, Eric, "Mars Ascent Vehicle Development Status," IEEEAC Paper \#1471, 2012 IEEE Aerospace Conference, Big Sky, MT, March $3-10,2012$.

[28] Mattingly, R. M., "Mars Sample Return MAV Study Guidelines,” JPL D-66683 Rev. B, May, 2011.

[29] Mungas, Greg, Fisher, David, Vozoff, Joanne, and Villa, Marco, "NOFBX" Single Stage to Orbit Mars Ascent Vehicle," IEEEAC Paper \#1809, 2012 IEEE Aerospace Conference, Big Sky, MT, March 3-10, 2012.

[30] Ross, Douglas, Russell, James, and Sutter, Brian, "Mars Ascent Vehicle (MAV): Designing for High Heritage and Low Risk," IEEEAC Paper \#1190, 2012 IEEE Aerospace Conference, Big Sky, MT, March 3-10, 2012.

[31] Trinidad, Mark A., Zabrensky, Ed, and Sengupta, Anita, "Mars Ascent Vehicle System Studies and Baseline Conceptual Design," IEEEAC Paper \#1744, 2012 IEEE Aerospace Conference, Big Sky, MT, March 3-10, 2012.

[32] Sengupta, Anita, Pauken, Mike, Kennett, Andrew, Trinidad, Mark A., and Zabrensky, Ed, "Systems Engineering and Technology Considerations of a Mars Ascent Vehicle," IEEEAC Paper \#1511, 2012 IEEE Aerospace Conference, Big Sky, MT, March 3-10, 2012.

[33] Ring, A. J., and Salem, J. A., "Yield Behavior of Solution Treated and Aged Ti-6Al-4V", NASA/TM2014-218322, April 2014

[34] Dankanich, J. W., Kamhawi, H., and Mathers, A., "HiVHAC Maximum Operating Power Mission Impacts," IEPC-2009-213, 2009 International Electric Propulsion Conference, Ann Arbor, MI, September 20-24, 2009.

[35] Whiffen, G., "Mystic: Implementation of the Static Dynamic Optimal Control Algorithm for High-Fidelity Low-Thrust Trajectory Design," AIAA-2006-6741, AIAA/AAS Astrodynamics Specialist Conference, Keystone, CO, August 21-24, 2006.

[36] Sims, J., Finlayson, P., Rinderle, E., Vavrina, M., and Kowalkowski, T., "Implementation of a Low-Thrust Trajectory Optimization Algorithm for Preliminary Design," AIAA-2006-6746, AIAA/AAS Astrodynamics Specialist Conference, Keystone, CO, August 21-24, 2006.

[37] Ocampo, C., Senent, J. S., and Williams, J., "Theoretical Foundation of Copernicus: A Unified System for Trajectory Design and Optimization," NASA Technical Reports Server, Document ID: 20100017708; Report Number: JSC-CN-20552, May, 21, 2010.
[38] "Vision and Voyages for Planetary Science in the Decade 2013-2022," The National Academies Press, URL: http://www.nap/edu, 2011 